\title{
Zoneamento de risco climático para a cultura do café Conilon no Estado do Espírito Santo ${ }^{1}$
}

\author{
Climatic risk zoning for Conilon coffee in Espirito Santo, Brazil
}

\author{
José Ricardo Macedo Pezzopane ${ }^{2 *}$, Fábio da Silveira Castro ${ }^{3}$, José Eduardo Macedo Pezzopane ${ }^{4}$, Robson \\ Bonomo $^{5}$ e Giselle Sabadim Saraiva ${ }^{6}$
}

\begin{abstract}
Resumo - O presente trabalho teve por objetivo apresentar um zoneamento de risco climático, baseado no atendimento hídrico para o café Conilon para o estado do Espírito Santo, em função da variação das necessidades de água nas fases fenológicas do florescimento, granação dos frutos e crescimento vegetativo. Foi realizada para cada fase fenológica uma análise frequencial da evapotranspiração relativa, obtida pela relação entre as evapotranspirações real e de referência, provenientes de um modelo de balanço hídrico sequencial. Posteriormente procedeu-se a espacialização de riscos climáticos de atendimento hídrico para o café Conilon considerando simultaneamente as fases fenológicas da floração, granação e crescimento vegetativo. Os resultados indicaram que devido à característica heterogênea do regime pluviométrico, associada às diferentes demandas hídricas, ocorre uma variação espacial do risco climático ao atendimento hídrico no Estado e que a partir da análise simultânea de atendimento hídrico nas diferentes fases fenológicas do café Conilon, identificou-se que 58\% da área do Espírito Santo, concentrada principalmente na região norte, apresenta alto risco climático nas fases vegetativa do florescimento, granação e crescimento vegetativo.
\end{abstract}

Palavras-chave - Balanço Hídrico. Granação. Florescimento. Evapotranspiração.

\begin{abstract}
A frequencial analysis of the crop water requirement index of the Conilon coffee (Coffea canephora), determined for the occurrence of relative evapotranspiration $(\mathrm{ETr} / \mathrm{ETo}) \geq 0.65$ above $80 \%$ of the years, was carried through for the phenological stages of the flowering, bean formation and vegetative growth. The areas with climatic risk of water deficit were zoned by a geographic information system considering simultaneously the three phenological stages. The results showed that due to heterogeneous rain characteristics, associate to the different water requirements, occurs a space variation of the climatic risk to the water required in the State. In analysis of water required in the different phonological stages of the Conilon coffee, it was identified that $58 \%$ of the area of the state of Espirito Santo, mainly in the north part, presents high climatic risk of water required in the phases of the flowering, bean formation and vegetative growth.
\end{abstract}

Key words - Water Balance. Bean Formation. Flowering. Evapotraspiration.

\footnotetext{
* Autor para correspondência

${ }^{1}$ Recebido para publicação em 01/12/2009; aprovado em 13/05/2010

Pesquisa financiada pela Fundação de Amparo à Pesquisa do Espírito Santo (FAPES)

${ }^{2}$ EMBRAPA Pecuária Sudeste, São Carlos-SP, Brasil, jricardo@cppse.embrapa.br

${ }^{3}$ Programa de Pós-Graduação em Produção Vegetal, Centro de Ciências Agrárias/UFES, Alegre-ES, Brasil, fabiosilveira_70@hotmail.com

${ }^{4}$ Departamento de Engenharia Rural/UFES, Alegre-ES, Brasil, jemp@cca.ufes.br

${ }^{5}$ Departamento de Ciências Agrárias e Biológicas/UFES, São Mateus-ES, Brasil, robsonbonomo@ceunes.ufes.br

${ }^{6}$ Acadêmica do curso de Agronomia/UFES, São Mateus-ES, Brasil, gizellesab@hotmail.com
} 


\section{Introdução}

No Brasil cerca de $30 \%$ da produção de café é derivada da espécie Coffea canephora, denominada de café robusta, que é cultivada predominantemente nos estados do Espírito Santo, Rondônia, Minas Gerais, Mato Grosso, Bahia e Rio de Janeiro. No Espírito Santo, maior produtor brasileiro da espécie, a produção é proveniente da variedade Conilon, pertencente ao grupo Guineano da espécie (BRAGANÇA et al., 2001).

A cultura do café Conilon está presente em 65 dos 78 municípios do Espírito Santo, em uma área aproximada de 290 mil hectares, sendo que na região sul é cultivado principalmente na bacia do rio Itapemirim, e na região norte do Estado os principais produtores são Jaguaré, Sooretama, Vila Valério, São Mateus, Rio Bananal e Pinheiros (FASSIO; SILVA, 2007).

Especificamente para a cultura do café, a aptidão agroclimática de regiões propicia delimitar áreas com padrão climático semelhante com base nos indicadores do meio físico para a região do estudo, permitindo, independente do nível tecnológico e de insumos a ser adotado, a identificação de regiões mais apropriadas para o cultivo onde se possibilitará a máxima eficiência agrícola. Essa ferramenta é chamada de zoneamento agroclimático.

Para o café arábica já foram realizados trabalho de zoneamento agroclimático para diversos estados brasileiros (ASSAD et al., 2001; CARAMORI et al, 2001; SEDIYAMA et al., 2001; PINTO et al., 2001), sendo que para o Espírito Santo, Taques e Dadalto (2007) apresentam o zoneamento agroclimático para o café conilon. Esses estudos indicam para a cultura, as áreas aptas, inaptas ou restritas, sem levar em consideração o aspecto probabilístico de ocorrência de extremos meteorológicos.

Mais recentemente $\mathrm{o}$ aspecto probabilístico começou a ser considerado em trabalhos de zoneamento, quantificando-se as chances de fenômenos adversos ocorrerem em fases críticas da cultura, sendo que esta metodologia foi denominada zoneamento de riscos agrícolas e não mais de potencial agrícola (MACEDO et al., 2001; PINTO et al, 2001).

Um dos critérios mais utilizados em estudos agroclimáticos deste tipo é o índice de satisfação das necessidades de água (ISNA) definido pela relação entre a evapotranspiração real e a evapotranspiração da cultura. Para a cultura do café o atendimento hídrico tem sido expresso pela relação entre a evapotranspiração real e a evapotranspiração de referencia ou potencial, denominada evapotranspiração relativa (CARVALHO et al., 2004; SANTOS; CAMARGO, 2006).
Sob o aspecto térmico a maior parte do estado do Espírito Santo apresenta condições ótimas para o cultivo da espécie. Sob o aspecto hídrico, principalmente no norte do estado, o cultivo do café Conilon tem ocorrido em regiões onde a deficiência hídrica é o principal fator limitante à produção, onde em muitos anos a ocorrência de secas prolongadas e veranicos tem prejudicado a produção dos cafeeiros em condições não irrigadas (DAMATTA; RAMALHO, 2006).

Notadamente dois estádios reprodutivos do café podem ser prejudicados com a ocorrência de estiagens: a floração e a granação dos frutos (DAMATTA et al., 2007). No primeiro, a ocorrência de estiagem após a florada faz com que haja menor pegamento dos frutos. Já na granação, a ocorrência de estiagem faz com que aumente a presença de frutos chochos e mal granados. Além desses dois estádios, o crescimento vegetativo do cafeeiro também pode ser prejudicado pela estiagem.

O presente trabalho tem por objetivo apresentar o zoneamento de risco climático para o café Conilon para o estado do Espírito Santo, em função da variação das necessidades de água em diferentes fases fenológicas da cultura.

\section{Material e métodos}

Para a realização do presente estudo foram utilizados dados de séries de temperatura média do ar e do total mensal de precipitação pluvial, considerando um período de 30 anos (1977-2006).

NoestadodoEspíritoSanto, os dados meteorológicos foram obtidos em 94 pontos de medição, sendo 11 pertencentes à rede de estações meteorológicas do Instituto Capixaba de Pesquisas e Extensão Rural (INCAPER), 3 pertencentes ao Instituto Nacional de Meteorologia (INMET) que forneceram medidas de temperatura média do ar e precipitação e outros 80 pertencentes à Agência Nacional das Águas (ANA), que forneceram somente dados de precipitação. Adotaram-se ainda outros 16 postos pluviométricos também pertencentes à ANA, localizados fora do Estado, totalizando 110 pontos de medida.

Pelo reduzido número de dados de temperatura disponíveis para o estado do Espírito Santo, optou-se por estimar os valores a partir de modelos matemáticos desenvolvidos para esta região (CASTRO, 2008).

A partir da tabulação dos dados de precipitação pluviométrica e temperatura média, ou de sua estimativa, para os 110 pontos de medida, procedeu-se a elaboração do balanço hídrico climatológico sequencial, com base mensal, para cada posto utilizando-se das rotinas em planilha EXCEL construídas por Rolim 
et al. (1998). A evapotranspiração de referência foi calculada pelo modelo proposto por Thornthwaite. De maneira geral é predeterminada a capacidade máxima de armazenamento de água no solo, que depende das características físicas dos solos e da profundidade do sistema radicular, sendo considerada neste estudo a capacidade máxima de armazenamento de $100 \mathrm{~mm}$ (CAMARGO; PEREIRA, 1994).

Antes de proceder a análise do risco ao atendimento hídrico foram selecionadas as áreas do Estado com temperatura média anual maior que $22{ }^{\circ} \mathrm{C}$, consideradas aptas sob o aspecto térmico (SANTINATO et al., 2008).

Do balanço hídrico, a variável mais importante para a definição de riscos é a relação entre a evapotranspiração real e a evapotranspiração de referência (ETr/ETo), denominada evapotranpiração relativa, por ser um indicador de atendimento da necessidade de água pela planta. Esta relação tem sido amplamente utilizada em trabalhos com modelos agrometeorológicos que relacionam fatores hídricos e produção de café (CARVALHO et al., 2004; PICINI et al., 1999; SANTOS; CAMARGO, 2006) todos baseados nos apontamentos de Camargo e Pereira (1994) que utilizam Kc igual à unidade em trabalhos de caráter climatológico para a cultura do café. A justificativa pra seu uso está baseada em literaturas que apresentam valores próximos à unidade ou variação desses valores em função de espaçamento de café, variedades ou manejo da entrelinha (ARRUDA et al.,2000; RENA; MAESTRI 2000; VILLA NOVA et al., 2002). É importante salientar que estes trabalhos foram realizados para a espécie Coffea arabica, visto que para a espécie Coffea canephora a literatura não apresenta esses valores.

No presente trabalho foram considerados os valores médios anuais da evapotranspiração relativa para três períodos, considerados críticos a ocorrência do déficit hídrico para a produção de café Conilon no estado: agostosetembro, período relacionado com a floração do cafeeiro; janeiro-fevereiro, período relacionado com a granação dos frutos e outubro-maio, período relacionado com o desenvolvimento vegetativo.

Efetuou-se a análise frequencial da evapotranspiração relativa para $80 \%$ de ocorrência. Foram definidas duas classes da relação ETr/ETo para diferenciação dos ambientes dentro do estado do Espírito Santo: ETr/ETo > 0,65, definida como região de pequeno risco climático, isto é, com atendimento hídrico e ETr/ETo $<0,65$, definida como alto risco climático, onde a probabilidade de atendimento hídrico é pequena devido a freqüente ocorrência de déficit hídrico.
Os valores de ETr/ETo calculados para cada ponto de medida foram espacializados, utilizandose a interpolação dos dados, por meio do método da krigagem modelo esférico, escolhido de acordo com os testes de Castro (2008), utilizando-se rotinas específicas de um SIG implementado através do software ArcGis 9.2/ArcMap pelo módulo "ArcToolbox - Spatial Analyst Tools - Interpolation", o qual deu origem ao mapa temático que representa as condições de probabilidade de atendimento hídrico para cada uma das três épocas do estudo.

Posteriormente, o mapa de atendimento hídrico para o café Conilon no Estado foi obtido através do cruzamento dos mapas das três épocas, definindo-se dentro da área de estudo as regiões de risco ou não ao atendimento hídrico da cultura.

\section{Resultados e discussão}

Na Figura 1 é apresentada a relação ETr/ETo para três épocas do ano, no período de 1977 a 2006, correspondentes às fases fenológicas da floração, granação e crescimento vegetativo do café para os municípios de Alegre, Rio Bananal e Nova Venécia, situadas nas regiões Sul, Centro-norte e Norte do estado do Espírito Santo. Esses três municípios estão localizados em regiões representativas da produção de café Conilon no Estado.

Para o período da floração (FIG 1A) a análise da frequencia mostra que a relação ETr/ETo foi maior que 0,65 em 50\%, 30\% e $17 \%$ dos anos em Alegre, Rio Bananal e Nova Venécia, respectivamente, indicando haver risco climático de não atendimento hídrico para as lavouras. É importante ressaltar que principalmente na região norte do Estado, com temperaturas mais elevadas, frequentemente lavouras de café florescem em agosto devido à ocorrência esporádica de chuvas, porém devido a baixa probabilidade de atendimento hídrico essas floradas tem poucas chances de vingamento em lavouras não irrigadas.

Para o período da granação (FIG 1B) a relação ETr/ETo foi maior que 0,65 em $87 \%, 76 \%$ e $70 \%$ dos anos em Alegre, Rio Bananal e Nova Venécia, respectivamente. Diferentemente da floração, em municípios do sul do Estado, com padrão de regime de chuvas bem semelhante a outro estado da região Sudeste do país (CASTRO, 2008), ocorreu atendimento hídrico na maioria dos anos.

Para o período do crescimento vegetativo (FIG 1C) a relação ETr/ETo foi maior que 0,65 em 100\%, 87\% e $60 \%$ dos anos em Alegre, Rio Bananal e Nova Venécia, 

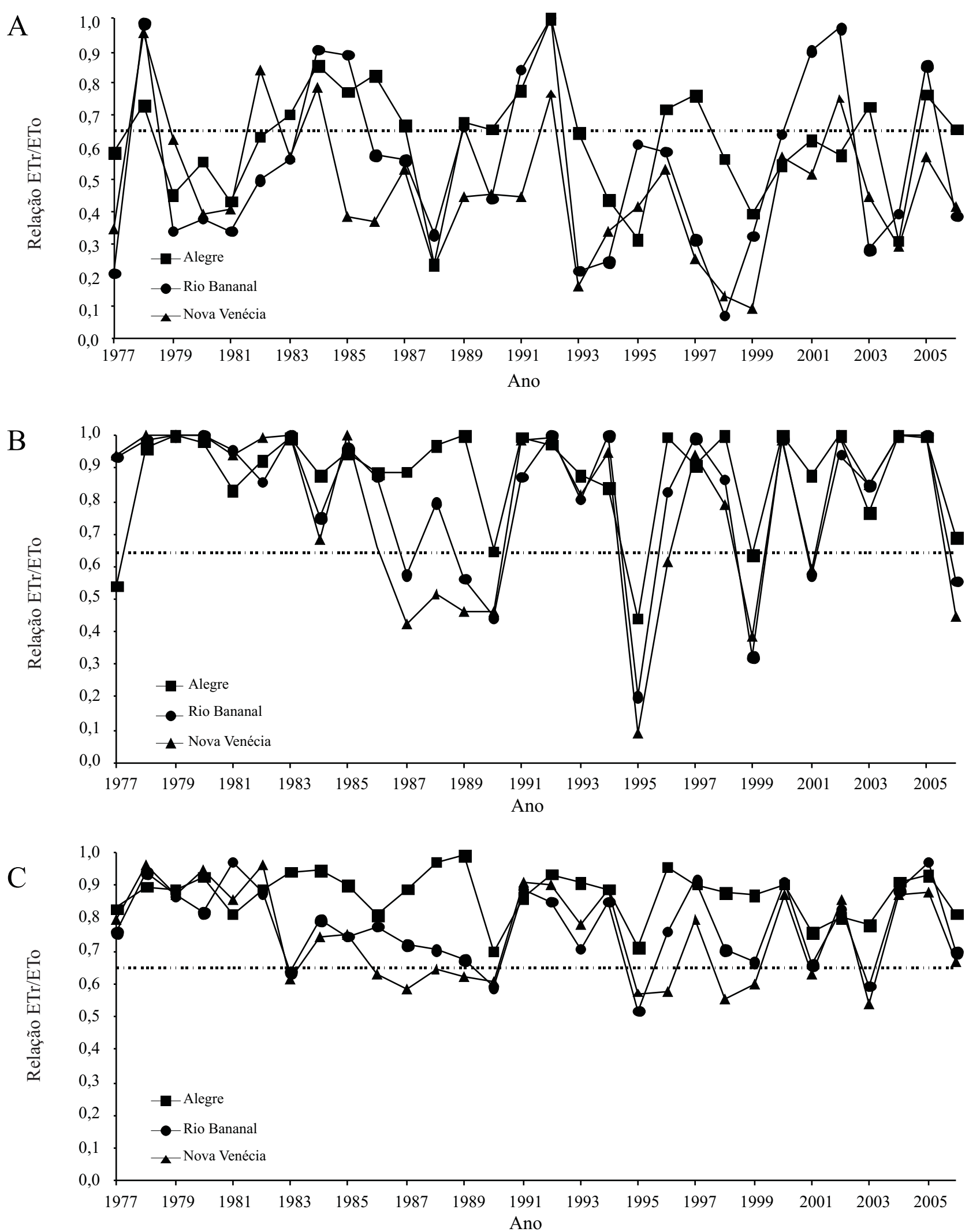

Figura 1 - Relação ETr/ETo para os meses de agosto a setembro (A), janeiro a fevereiro (B) e outubro a maio (C) correspondente às fases de floração, granação e crescimento vegetativo do café Conilon, respectivamente, nos anos de 1977 a 2006, nos municípios de Alegre, Rio Bananal e Nova Venécia, ES 
respectivamente. Em análise à Figura 1 verifica-se para Nova Venécia que em nenhuma das três fases analisadas ocorre atendimento hídrico ao café Conilon em $80 \%$ dos anos, indicando que para o município o risco climático de ocorrência de secas é alto.

Na Figura 2 é apresentada a espacialização da análise de freqüência de ocorrência da relação ETr/ETo $>$ 0,65 para os meses de agosto a setembro correspondente à fase de floração do café Conilon no estado do Espírito Santo.

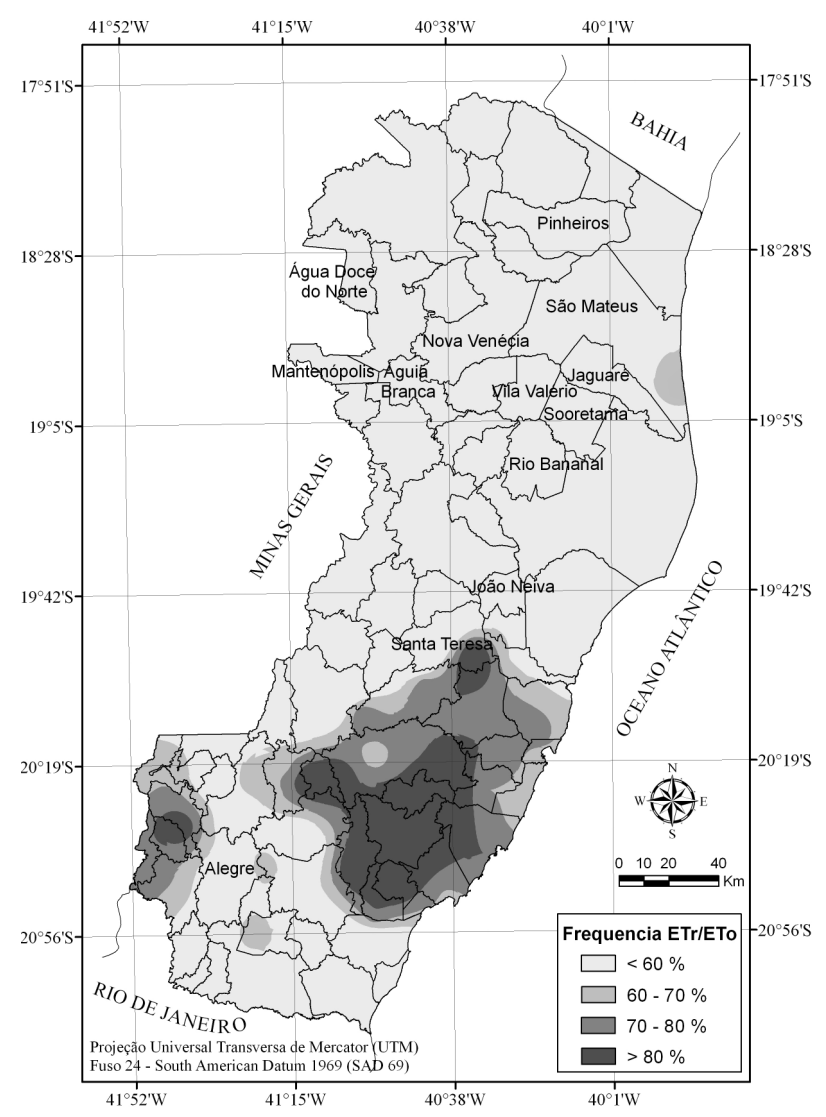

Figura 2 - Distribuição espacial da freqüência de ocorrência da relação ETr/ETo $>0,65$ para os meses de agosto a setembro correspondente à fase de floração do café Conilon no estado do Espírito Santo

Para os meses de agosto e setembro, correspondentes à fase da floração (FIG 2) a grande maioria das áreas do estado apresenta menos de $60 \%$ de ocorrência da relação $\mathrm{ETr} / \mathrm{ETo}>0,65$, indicando risco climático ao atendimento hídrico. Embora o risco matematicamente ocorra em todas as regiões, sua ocorrência na região norte do Estado é mais significativa que na região sul do Estado. Devido às elevadas temperaturas (CASTRO, 2008) e à ocorrência de chuvas esporádicas no período de inverno, é comum a ocorrência de florescimentos significativos em agosto na região norte do Estado.

Para os meses de janeiro e fevereiro, correspondentes à fase fenológica da granação dos frutos (FIG 3), as áreas das regiões sul e central do Estado (até os municípios de Santa Teresa e João Neiva) que são aptas, sob o aspecto térmico, para o plantio do café Conilon (temperaturas médias anuais superiores a $22{ }^{\circ} \mathrm{C}$ ) não apresentam risco climático de atendimento hídrico, exceto a região litorânea. $\mathrm{O}$ atendimento hídrico também ocorre em alguns municípios da região noroeste do Estado na divisa com Minas Gerais (Mantenópolis, Águia Branca e Água Doce do Norte). Na região norte do Estado ocorre o risco climático, que é mais evidente na região litoral norte, onde a frequencia de ocorrência da relação ETr/ETo > 0,65 esta entre 60 e 70\% dos anos.

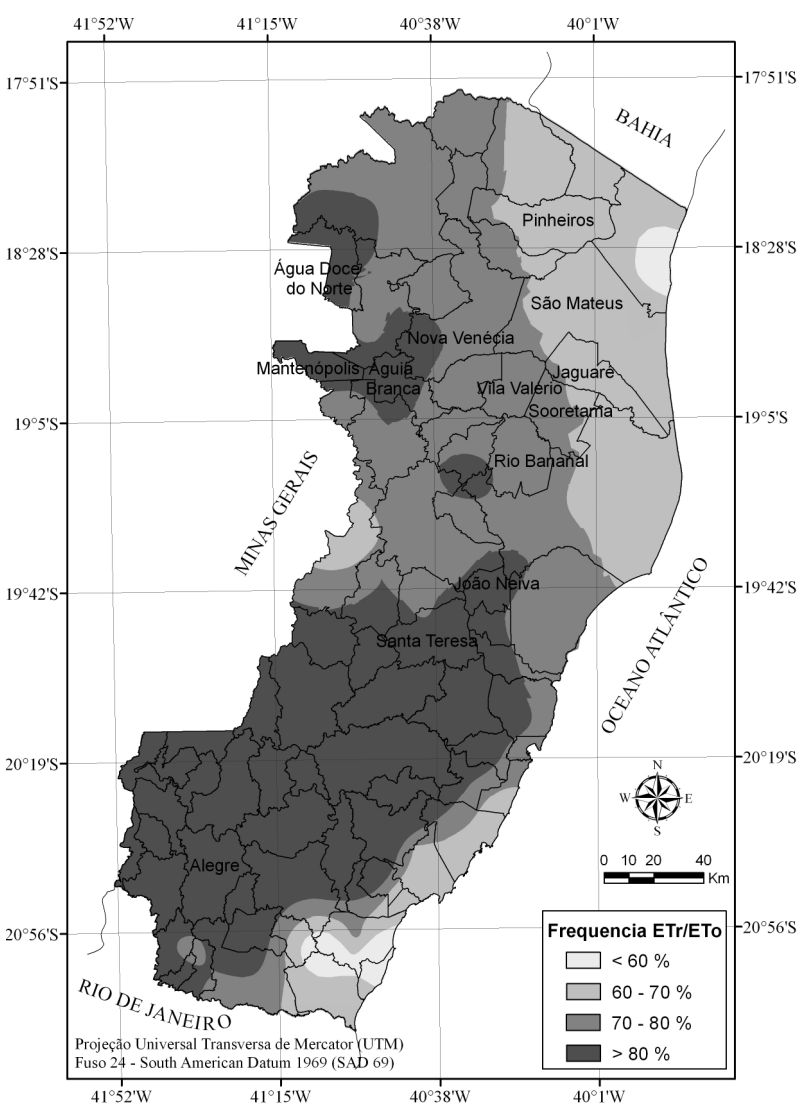

Figura 3 - Distribuição espacial da freqüência de ocorrência da relação $\mathrm{ETr} / \mathrm{ETo}>0,65$ para os meses de janeiro a fevereiro correspondente a fase de granação do café Conilon no estado do Espírito Santo 
Para o período outubro a maio (FIG 4), correspondente ao crescimento vegetativo, aumenta a área no Estado com menor risco climático de atendimento hídrico (ETr/ETo > 0,65 em 80\% dos anos). Assim como na granação as regiões sul e central (até o município de Rio Bananal) do Estado apresentam baixo risco climático. A região norte do Estado, onde se encontram os maiores municípios produtores de café Conilon, como Jaguaré, Vila Valério, São Mateus, Pinheiros e Sooretama (FASSIO; SILVA, 2007) ainda ocorre alto risco ao atendimento hídrico.

Para período do crescimento vegetativo, os municípios do vale do Rio Doce, no oeste do Estado também apresentam alto risco climático, com as menores relações ETr/ETo para o período no Estado.

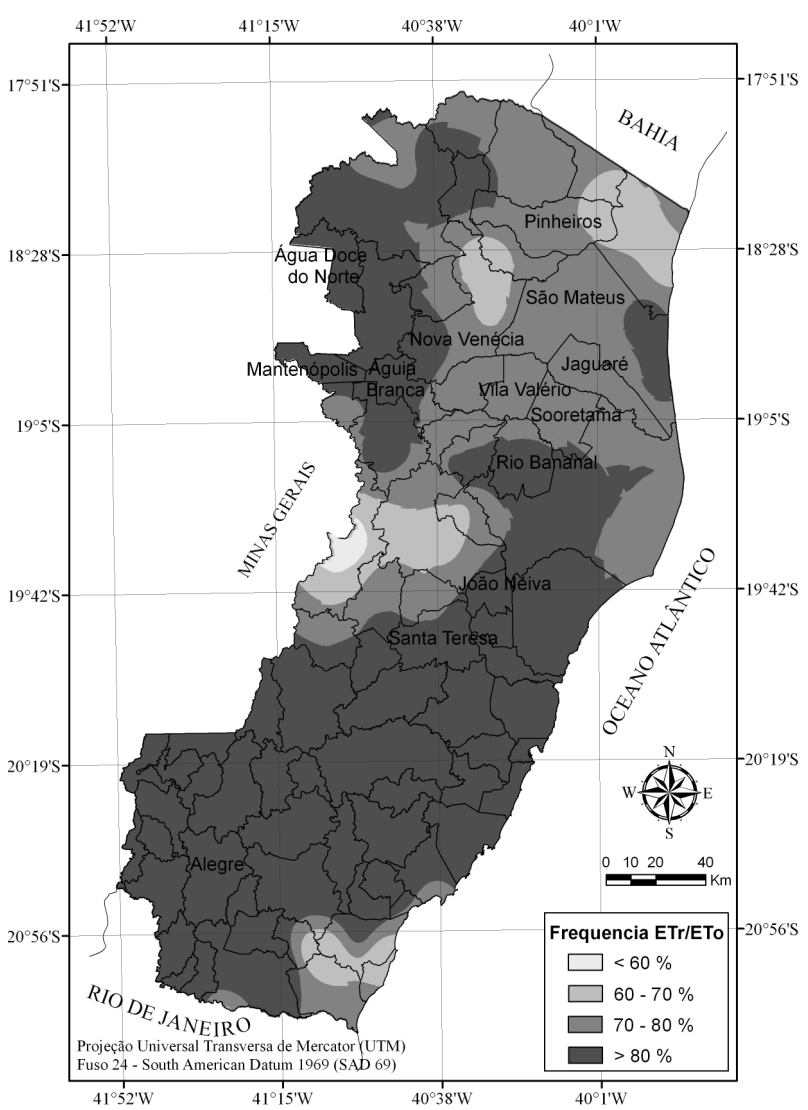

Figura 4 - Distribuição espacial da freqüência de ocorrência da relação $\mathrm{ETr} / \mathrm{ETo}>0,65$ para os meses de outubro a maio correspondente ao crescimento vegetativo do café Conilon no estado do Espírito Santo

Na Figura 5 é apresentada a espacialização de riscos climáticos de atendimento hídrico para o café
Conilon no estado do Espírito Santo considerando simultaneamente as fases fenológicas da floração, granação e crescimento vegetativo.

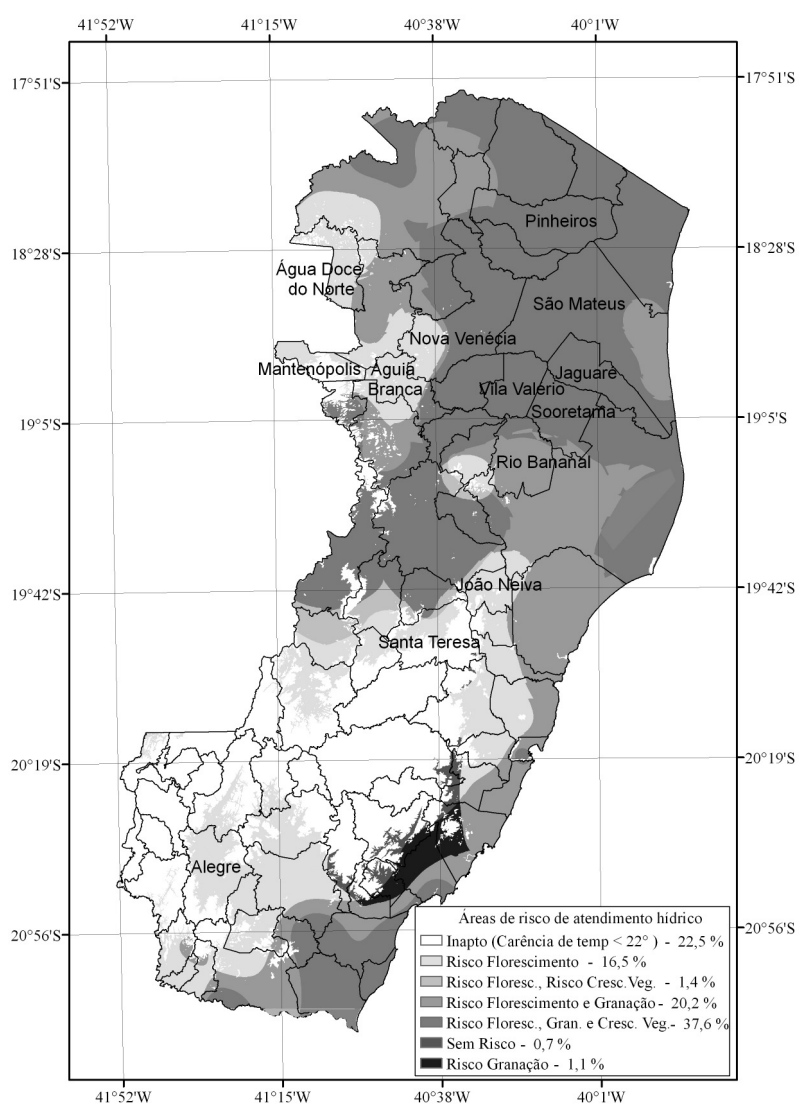

Figura 5 - Espacialização e porcentagem das áreas de riscos climáticos (valores entre parêntesis) de atendimento hídrico para o café Conilon no estado do Espírito Santo considerando simultaneamente as fases fenológicas da floração, granação e crescimento vegetativo

Devido à característica heterogênea do regime pluviométrico e às diferentes demandas hídricas, os resultados indicam uma variação espacial do risco climático para a cultura do café Conilon no Espírito Santo. Sob o aspecto térmico, o Estado apresenta cerca de $77 \%$ da área apta para o cultivo do café Conilon.

Sob o aspecto hídrico, o Estado apresenta elevado risco climático para a cultura do café Conilon. Dentre as categorias de risco apresentadas, a maior área (38\%) apresenta elevado risco climático nas fases do florescimento, granação e crescimento vegetativo, seguido de $20 \%$ com risco nas fases de florescimento e granação e $17 \%$ com risco no florescimento. 
Se for considerado que as áreas onde ocorre risco somente no período do florescimento estão mais concentradas no sul do estado, onde a ocorrência de floradas ocorre no mês de setembro, esse risco é minimizado.

Quando consideradas as épocas de ocorrência do risco na florada-granação e florada-granação-crescimento vegetativo encontra-se uma área total de $58 \%$ do Estado, concentrada principalmente na região norte onde estão os maiores municípios produtores, pois, de acordo com os levantamentos de Fassio e Silva (2007) mostram que na região norte do Estado estão plantados cerca de $160 \mathrm{mil}$ dos 290 mil ha de café Conilon.

Os dados encontrados neste trabalho vêm de acordo com as constatações de Silva e Reis (2007) que verificaram que em praticamente toda a região produtora do café Conilon no Espírito Santo existe alguma limitação de produtividade devido ao déficit hídrico, podendo, nesses casos, ser necessário o emprego da técnica da irrigação. Levantamentos de campo indicam que no Espírito Santo a área irrigada de café varia de 95 mil ha (SANTINATO et al., 2008) a 120 mil ha (SILVA; REIS, 2007), indicando haver ainda grande potencial ao uso desta prática nas áreas de produção de café Conilon, em função dos resultados aqui obtidos.

\section{Conclusões}

1. Devido à característica heterogênea do regime pluviométrico, associado às diferentes demandas hídricas, ocorre uma variação espacial do risco climático ao atendimento hídrico para a cultura do café Conilon no Espírito Santo.

2. Por meio da análise simultânea de atendimento hídrico nas diferentes fases fenológicas do café Conilon, verifica-se que $58 \%$ da área do Espírito Santo, concentrada principalmente na região norte, apresenta alto risco climático nas fases vegetativa do florescimento, granação e crescimento vegetativo.

\section{Referências}

ARRUDA, F. B. et al. O. Resultados anuais do coeficiente de cultura do cafeeiro em um ensaio em Pindorama/SP. In: SIMPÓSIO DE PESQUISAS DOS CAFÉS DO BRASIL, 1., 2000, Poços de Caldas, Anais... Brasília: Embrapa Café/ Minasplan, 2000. p. 790-793. 2 v.

ASSAD, E. D. et al. Zoneamento agroclimático para a cultura do café (Coffea arabica L.) no Estado de Goiás e sudoeste do Estado da Bahia. Revista Brasileira de Agrometeorologia, v. 09, n. 03, p. 510-518, 2001
BRAGANÇA, S. M. et al. EMCAPA 8111, EMCAPA 8121, EMCAPA 8131: Variedades clonais de café Conilon para o Estado do Espírito Santo. Pesquisa Agropecuária Brasileira, v. 36, n. 05 , p. $765-770,2001$.

CAMARGO, A. P.; PEREIRA, A. R. Agrometeorology of the coffee crop. Geneva: World Meteorological Organization, 1994. 99 p. (Agricultural Meteorological CAgM Report, 58).

CARAMORI, P. H. et. al. Zoneamento de riscos climáticos para a cultura de café (Coffea arabica L.) no Estado do Paraná. Revista Brasileira de Agrometeorologia, v. 09, n. 03, p. 486-494, 2001.

CARVALHO, L. G. et al. Modelo de regressão para a previsão de produtividade de cafeeiros no estado de Minas Gerais. Revista Brasileira de Engenharia Agrícola e Ambiental, v. 08, n. 02/03, p. 204-211, 2004.

CASTRO, F. S. Zoneamento agroclimático para a cultura do Pinus no Estado do Espírito Santo. 2008. 99 f. Dissertação (Mestrado em Produção Vegetal) - Universidade Federal do Espírito Santo, Alegre.

DAMATTA, F. M.; RAMALHO, J. D. C . Impacts of drought and temperature stress on coffee physiology and production: a review. Brazilian Journal of Plant Physiology, v. 18, n. 01, p. $55-81,2006$.

DAMATTA, F. M. et al. Ecophysiology of coffee growth and production. Brazilian Journal of Plant Physiology, v. 19, n. 04, p. 485-510, 2007.

FASIO, L. H.; SILVA, A. E. S. da. Importância econômica e social do café Conilon. In: FERRÃO, R. G. et al. (Ed.). Café Conilon. Vitória, ES: Incaper, 2007. cap. 1, p. 37-52.

MACEDO, M. A. et al. Avaliação de métodos para espacialização dos índices de necesidade de água das culturas e sua aplicação no zoneamento agrícola. Revista Brasileira de Agrometeorologia, v. 09, n. 03 , p. $581-587,2001$.

PICINI, A. G. et al. Desenvolvimento e teste de modelos agrometeorológicos para a estimativa de produtividade do cafeeiro. Bragantia, v. 58, n. 01, p. 157-170, 1999.

PINTO, H. S. et al. Zoneamento de riscos climáticos para a cafeicultura do Estado de São Paulo. Revista Brasileira de Agrometeorologia, v. 09, n. 03, p. 495-500, 2001.

RENA, A. B.; MAESTRI, M. Fisiologia do cafeeiro. Informe Agropecuário, v. 11, n. 126, p. 26-40, 1985.

ROLIM, G. S.; SENTELHAS, P. C.; BARBIERI, V. Planilhas no ambiente EXCELTM para os cálculos de balanços hídricos: normal, seqüencial, de cultura e de produtividade real e potencial. Revista Brasileira de Agrometeorologia, v. 06, n. 01, p. 133-137, 1998.

SANTINATO, R., FERNANDES, A. L. T., FERNANDES, D. R. Irrigação na cultura do café. 2 . ed. Uberaba: O Lutador, 2008. 483 p.

SANTOS, M. A.; CAMARGO, M. B. P. Parametrização de modelo agrometeorológico de estimativa de produtividade do 
cafeeiro nas condições do Estado de São Paulo. Bragantia , v. 65, n. 01, p. 173-183, 2006.

SEDIYAMA, G. C. et al. Zoneamento agroclimático do cafeeiro (Coffea arabica L.) para o Estado de Minas Gerais. Revista Brasileira de Agrometeorologia, v. 09, n. 03, p. 501-509, 2001.

SILVA, J. G. F.; REIS, E. F. Irrigação do cafeeiro Conilon In: FERRÃO, R. G. et al. Café Conilon. Vitória, ES: Incaper, 2007. cap. 3, p. 347-376.
TAQUES, R. C., DADALTO, G. G. Zoneamento agroclimatológico para a cultura do café Conilon no Estado do Espírito Santo. In: FERRÃO, R. G. et al. Café Conilon. Vitória, ES: Incaper, 2007. cap. 3, p. 53-66.

THORNTHWAITE, C. W.; MATHER, J. R. The water balance. New Jersey: Centerton, 1955. 104 p. (Publications in Climatology, v. 08, n. 01).

VILLA NOVA, N. A. et al. Estimativa do coeficiente de cultura do cafeeiro em função de variáveis climatológicas e fitotécnicas. Bragantia, v. 61, n. 01, p. 81-88, 2002. 